\title{
ПОСТРЕВОЛЮЦИОННАЯ ДЕЙСТВИТЕЛЬНОСТЬ ГЛАЗАМИ „МАЛЕНЬКОГО ЧЕЛОВЕКА”. МЕМУАРНАЯ ПРОЗА ВЕНИАМИНА КОРСАКА
}

\author{
POST-REVOLUTIONARY REALITY \\ IN THE EYES OF A „LITTLE MAN”. \\ VENIAMIN KORSAK'S MEMOIR NOVELS
}

ANTONI BORTNOWSKI

\begin{abstract}
AвSTRACт. Veniamin Korsak is a writer who represents the Russian literature of the first wave of emigration and is known primarily through a series of five autobiographical novels presenting the story of a simple man who went into German captivity during World War I and then returned to Russia, which was overwhelmed by civil war. Korsak's works are a testimony of a "little man", looking at reality through the prism of ordinary everyday affairs, instinctively trying to survive in the historical turmoil. This article is an attempt to show the specificity of this perspective on the basis of his novels.
\end{abstract}

Keywords: Veniamin Korsak, memoirs, "little man”, émigré literature

Antoni Bortnowski, Uniwersytet im. Adama Mickiewicza w Poznaniu, Poznań - Polska, a.bortnowski@amu.edu.pl

ORCID ID: 0000-0002-9963-1798

Уже более четверти века продолжается процесс воссоединения русской литературы. Благодаря исследователям-эмигрантологам вернулись и продолжают возвращаться из небытия фамилии многих писателей, чьи произведения в советское время были забыты или просто запрещены. Сегодня творчество самых выдающихся представителей первой волны русской эмиграции уже известно не только литературоведам, но и широкому кругу читателей. Мечта писателей-изгнанников - быть услышанными на родине - в большой степени уже осуществилась. Однако литература это не только звезды первой величины, но также второстепенные писатели, талант которых не столь однозначен, а именно: авторы одного или нескольких произведений, замеченных и положительно принятых современниками, но затерявшихся в волне шедевров, хлынувших в Россию в период возвращения на родину эмиграционной литературы. 
Одним из таких писателей, безусловно, является Вениамин Валерианович Завадский, писавший под псевдонимом Корсак. Его судьба напоминает историю многих интеллигентов, оказавшихся после революции за пределами России. Отец Вениамина Завадского был поляком, а мать происходила с Дона. Будущий писатель учился на юридическом факультете Варшавского университета, а затем стал простым служащим в страховом агентстве. Летом 1914 года Завадский был мобилизован и попал на фронт, а уже в ноябре оказался в плену. Спустя четыре года, в июле 1918го, немцы отправляют его, как больного, уже в советскую Россию. Там Корсак, в связи с непригодностью к военной службе, работает в одном из комиссариатов Могилевской губернии. Потом Завадский попадает в Киев, где становится свидетелем прихода белых, затем вместе с Добровольческой армией уходит на юг - в Одессу. Портовой город становится для него, как и для многих других эмигрантов (например, Бунина), последним пристанищем в России. Оттуда Вениамин Завадский эвакуируется в Египет, а затем попадает во Францию, где становится плодовитым и популярным писателем [Носик 2005: 197]. Похоронен Корсак на кладбище Сент-Женевьев-де-Буа в Париже.

Корсак известен прежде всего своим мемуарным пятикнижием, описывающим жизнь писателя в плену (Плен, 1927; Забытые, 1928) и в период гражданской войны (У красных, 1930; У белых, 1931; Великий исход, 1931). Повести были высоко оценены эмигрантской критикой. „Пять книг составляют... не только завершенный образ неповторимого... жития, но и страшный документ недавнего прошлого, в ряду подобных документов - один из ценнейших и достовернейших", - писал в Современных записках Михаил Осоргин [Осоргин 1933: 461]. Достоинства повестей отметил также Марк Алданов: „Корсак пишет объективно о врагах; не приукрашивает он и своих. [...] ...[Писатель] справился с темой очень трудной и мрачной" [Алданов 1928: 500].

Одним из первых изданий Корсака в постсоветской России стали книги из серии Голоса истории, в которых появились сначала Плен и Забытые (Забытая война, 2011), а затем У красных, У белых, Великий исход (Красная смута, 2011). Первые же отзывы о „вернувшихся” произведениях во многом повторили точку зрения эмигрантской критики, отмечая, что Корсак передает впечатления „без всяких собственных комментариев, рассуждений, он никак не оценивает происходившее, справедливо полагая, что эти факты красноречивы сами по себе" [Морозова 2012].

Именно объективность и беспристрастность Корсака следует считать одним из основных достоинств его произведений, которые в результате, как уже было сказано, могут рассматриваться в качестве ценного документа своего времени. В отличие от многочисленных в литературе 
первой волны эмиграции автобиографий, в повестях Корсака главный герой не сосредоточен на своей личности и обстоятельствах, влияющих на ее развитие. Как заметил на вечере, посвященном памяти Вениамина Завадского, известный деятель эмиграции Сергей Мельгунов,

Корсак нигде не рядится в искусственную тогу высокопарных гражданско-патриотических чувствований; все у него жизненно просто. Он описывает то, что видел собственными глазами, то, что чувствовал непосредственно. Это придает его повествованию характер какой-то большой искренности и правдивости [см. Зверев 1990: 62].

Итак, в мемуарных произведениях Корсака представлена перспектива хоть и наблюдательного, но все же обыкновенного, простого человека. Он в какой-то степени сам себя не понимает, но и не стремится изменить такого положения вещей. В результате читатель не погружается в мир размышлений и оценок героя-повествователя, а скорее приглашается к совместному наблюдению за происходящими событиями и к сопереживанию элементарных человеческих чувств и эмоций: страха, злости, иногда любопытства. Скитания главного героя Корсака являют собой полюс, полностью противоположный в отношении к сугубо субъективному путешествию вглубь себя, который мы находим, например, в романе Гайто Газданова Вечер у Клэр. „Сырая” картина действительности в повестях Корсака, лишенная однозначных оценок, создает ощущение достоверности и объективности, хотя и подводит читателя к конкретным выводам. Многочисленные в произведениях Корсака яркие картины жизни в условиях Гражданской войны говорят сами за себя и, скорее всего, не случайно были подобраны автором. Однако кажется, что герой-повествователь (он ведь моложе автора на целых 10 лет) еще не совсем осознает значения происходящего вокруг. Таким образом писатель передает ощущения простого человека, который находится в центре свершающихся исторических потрясений и борется за существование, а не пытается с перспективы времени осмыслить исторические события, свидетелем которых ему пришлось стать.

Представленная в повестях $У$ красных, У белых и Великий исход широкая панорама распадающейся и охваченной гражданской войной страны показана с перспективы „маленького человека”. У героя-повествователя ярко выражены типичные черты данного типа героя, такие как низкое положение в социальной иерархии, бедность, незащищённость, роль жертвы социальной несправедливости и бездушного государственного механизма, страх перед жизнью, приниженность. Ему чужда любая идеология, герой Корсака не хочет вникать в суть исторических потрясений, частью (а тем более субъектом) которых себя абсолютно не ощу- 
щает. Это заметно уже в повести Плен, когда он делится впечатлениями перед отправкой на фронт Первой мировой: „Предстоявшая война казалась чем-то, вроде увеселительной прогулки, с ночевками в поле" [Корсак 1927: 7]. Герой Корсака хочет просто жить, не желает никому зла, стремится быть честным, не требовать и не ожидать от жизни лишнего. Вместе с тем он не умеет заступиться ни за себя, ни за других. Именно поэтому, как замечает один из подобных герою персонажей, такие люди чаще всего обречены. „Мне же и вам придется погибнуть, ибо, скажите, что делать людям, у которых ничего, кроме вшей и совести, не осталось" [Корсак 1931].

Во многом в результате своей жизненной позиции герой захвачен течением событий, и лишь по счастливому стечению обстоятельств и благодаря не совсем осознанному инстинкту самосохранения он из белорусской глубинки попадает в итоге на английское госпитальное судно в одесском порту. По дороге ему приходится побывать и у красных, и у белых и даже столкнуться с петлюровцами; наблюдать страдания евреев и видеть поляков, направляющихся на обретшую вновь независимость родину. Удивительно, что весь этот путь герой прошел, не совсем понимая, куда и зачем он направляется, так как к действию его побуждали почти исключительно крайняя необходимость или случайные обстоятельства. Мемуарные повести Корсака показывают, в какой растерянности и безысходности находятся простые люди, вырванные историческими потрясениями из своей привычной среды и в связи с этим не способные что-либо предпринять. Примером может стать поведение героя в Киеве после вступления в город белых:

...Приглашали записываться в городскую милицию. Я подумал - не пойти ли записаться, чтобы быть при каком-нибудь деле; подумал - и не пошел, сам не знаю, почему [Корсак 1931: 8].

Данный фрагмент хорошо показывает логику простого человека, о которой шла речь ранее: он не рассматривает службу в качестве долга перед Отечеством, не стремится защищать горожан от грабежей - ему лишь хочется избежать скуки. В данном случае инертность победила, и герой предпочел просиживать целыми днями в квартире у знакомых и ждать развития событий. Приведенный фрагмент в очередной раз подчеркивает несомненное достоинство произведений Корсака, заключающееся в их достоверности. Автор, возвращаясь к событиям десятилетней давности, не стремится приукрасить своего героя, дополнить его поступки и решения глубинным значением, переосмыслить их с перспективы времени, своего жизненного опыта или, тем более, каких-либо политических убеждений. 
Пассивное отношение главного героя мемуарных повестей к действительности вытекало во многом из условий, в которых оказался персонаж Корсака. Следует помнить, что, вернувшись в Россию в 1918 году, он попал в совершенно незнакомую обстановку. За четыре года в немецком плену на родине наступил экономический коллапс, Россия проиграла войну, пала монархия, прошли две революции и началась кровавая гражданская война. Понять и вписаться в новые реалии простому человеку определенно было нелегко. Вместе с тем, вернувшийся из плена герой мог трезво взглянуть на обстановку и в какой-то степени извне оценить перемены в стране.

Уже первые впечатления после пересечения границы Советской России не имеют ничего общего с радостным возвращением на родину. Герой словно покидал пределы цивилизованного мира (это притом, что он возвращался из плена) и попадал в мир упадка и хаоса:

Тут уже все было другое, даже воздух. Скверно запахло невычищенными уборными. На путях валялись порванные газеты, старые бинты, обрывки рогож, окурки, шелуха от семечек [Корсак 1930: 5].

Герой инстинктивно пытается найти осколки прошлого, частицы знакомого ему мира. Значимым в данном контексте становится образ разгромленного вагона первого класса, напоминавшего о погибшей дореволюционной России:

На полу - масса порванных, замасленных бумаг; полуразбитая бутылка из под коньяку „Мартель”, грязные портянки и около них - дорогой, полуразорванный шелковый женский шарф. [...] От тонкой, нежной материи еще шел запах духов. Открыл первое купе... - обивка с одного дивана была полусодрана, на другом - валялась селедочная головка и рыбьи кости; тут же пузырек из-под кокаина. Воздух - смесь махорки, селедки, немытых ног [Корсак 1930: 8-9].

Образ ситуации дополнило угощение вернувшихся пленных, получивших несъедобный, черный как деготь хлеб [Корсак 1930: 11], после которого они услышали речь молодого агитатора:

Товарищи, вы находитесь теперь в самой свободной стране. [...] Теперь никто не в состоянии вырвать у вас ваш кусок хлеба. Вы сами станете есть его. Вы не станете помирать от голода, как помирали от царского режима. Долой паразитов! Да здравствует вождь пролетариата Ленин! [Корсак 1930: 12]

Гробовое молчание, наступившее после пламенной речи комиссара, не только указывает на пропасть непонимания между большевиками и голодающим народом, но и подчеркивает трагизм вернувшихся из плена солдат, понявших, что они никому не нужны и худшее только впереди. 
Согласно логике мировосприятия „маленького человека”, критика большевиков и их политики в повести $У$ красных не осуществляется с позиций идейного оппонента. В произведении нет рассуждений о нюансах их идеологии, о правильности тех или иных пунктов политической программы. Есть ощущение глубокой человеческой несправедливости и констатация пагубного влияния новой власти на жизнь простых людей. Последствия большевистского владычества герой воспринимает как симптомы смертельной болезни, поразившей его родину. В Гомеле он констатирует, что „дух жизни, видимо, отлетал от города” [Корсак 1930: 121]. Попав, в свою очередь, в Могилев, он замечает, что „город, как будто болел и хирел, покрывшись, вместо болячек вывесками бесчисленных советских учреждений" [Корсак 1930: 111]. Советская бюрократия словно паразитирует на простых людях, беспрерывно размножаясь и представая перед населением в лице все новых непонятных учреждений, типа Совета народного хозяйства.

Жители и сами служащие называли Совнархоз более коротким и, пожалуй, более подходящим именем - Сорнавоз [Корсак 1930: 92].

При новой власти, в начале многими воспринимаемой несерьезно, благополучная жизнь провинциального селения на глазах героя-повествователя становится голодным существованием в условиях всеобщего террора.

В жизнь вошло мертвое начало. [...] Тысячи новых неуклюжих правил оплели человеческую жизнь; ...они убивали труд и вели за собой голод, страшный и неотвратимый голод [Корсак 1930: 107].

Жестокость большевиков, многократно и часто довольно натуралистично описанная на страницах повести, дополняет картину постреволюционной действительности. Даже в Киеве, где на первый взгляд жизнь показалась герою нормальнее, всеобщий террор буквально чувствуется в воздухе.

Неожиданно, по верхушкам тополей пронесся ветерок; но вместо прохлады он принес удушливый отвратительный запах со странным сладковатым привкусом. [...] ...Это из анатомического театра. Туда большевики казненных отвозят. Несколько сот трупов там гниет уже с самой весны [Корсак 1930: 149-150].

Киевский анатомический театр становится, таким образом, так же, как и в Белой гвардии (1925) Михаила Булгакова, символом бесчеловечности и духовной выхолощенности большевистской власти. В таких условиях, несмотря на свою пассивность, герой стремится (в большей 
степени бессознательно) найти в распадающейся действительности какую-нибудь универсальную опору. Что интересно, такую роль в цикле Корсака играет Киев как символ древней русской духовности, которая неоднократно в истории доказывала свою неистребимость. Город в глазах героя - это

...вещий Олег, святая Ольга, крещение Руси, Владимир с дружиной, Ярослав Мудрый. Киев - это не какой-нибудь, родства не помнящий, или дорвавшийся до власти выскочка, убивающий ребенка за одно слово. Киев - это старый Рюрикович, это - Лавра, это народная святыня... [Корсак 1930: 147]

Золотые купола древнего города и величественный Днепр неоднократно дают силу и надежду главному герою и другим киевлянам, оказавшимся под властью красных.

Неудивительно, что в условиях голода и всеобего террора горожане с воодушевлением ожидали прихода белых.

У всех было радостное настроение, как в Пасхальную ночь. Важным казалось не то, что чрезвычайки, расстрелы, пытки и гнет отошли в прошлое, самым важным было то, что ушли ложь и обман, без меры настаивавшие, что они единственная правда [Корсак 1930: 161-162].

Именно чувство глубокой несправедливости, фальши вызывало наибольший протест в сознании „маленького человека”. Он мог вынести многое, но не мог смириться с неестественной и чужой с его точки зрения природой новой власти:

Бездушный и безрадостный материализм, казнивший и убивавший без всякого милосердия людей, казался тенью, лишь временно затмившей людское сознание [Корсак 1930: 154].

Действительность, однако, не оправдала ожиданий героя, как и не оправдала их власть белых. Если характерной чертой красных была хладнокровная жестокость и стремление силой заставить людей жить по-новому, то их оппонентов отличала в восприятии Корсака полная беспомощность. С точки зрения простого человека, представленной в повести $У$ белых, совершенно непонятно, к чему стремятся противники большевиков и вообще, надо ли им что-либо, кроме максимального наслаждения жизнью перед приходом красных. Картина, изображенная Корсаком, во многом совпадает с образом полного идейного разложения белых в повести советского писателя Дмитрия Малышкина Падение Даи$p a$, хотя и создана представителем русской эмиграции. 
И хотя грозные события неотвратимо надвигались на Киев, город веселился, как никогда. Пестрые громадные афиши возвещали о бесчисленных балах, концертах, спектаклях. Все театры и кино были набиты битком. Все словно торопились жить. Залы, где давались балы и концерты, снаружи и внутри были залиты огнями, а весь город пропадал во тьме [Корсак 1931: 154-155].

Неудивительно, что следствием устроенного верхушкой белых „Пира во время чумы”, стало полное уничтожение их авторитета в глазах простых людей. Никто не хотел защищать обанкротившуюся власть, не способную даже одеть своих солдат. Это стало особенно заметно в ожидающей нашествия большевиков Одессе:

Добровольческие власти задумали произвести мобилизацию... Население отнеслось к ней совершенно равнодушно, и, прочтя объявление, многие с усмешкой отходили прочь. [...] ...[Оно] уже привыкло к приказам подобного рода, и все обещания расстреливать его вдоль и поперек не производили больше впечатления [Корсак 1931].

Общим для всех властей в постреволюционной России является крайнее неуважение к простому человеку, а также контраст между жизнью привилегированной верхушки и голодающих, брошенных на произвол судьбы низов. В восприятии героя Корсака жизнь чекистов, любивших не только дорогие вина и икру, но также чистый спирт и кокаин [Корсак 1930: 142], несильно отличалась от существования членов белогвардейской Государственной стражи, сумевших в условиях гражданской войны накопить внушительное имущество. Даже во время отступления из Киева они резко выделялись на фоне волны беженцев:

Вся Государственная стража была здоровая, упитанная, хорошо одетая; она резко отличалась от изнуренных и потрепанных солдат и офицеров Добровольческой армии.

$[\ldots]$

...Вся картина имела скорее вид торгового каравана, пробиравшегося в неизвестные земли, чем уходившего от неприятеля войска [Корсак 1931].

На этом фоне становится особенно заметным трагизм простых людей, которые до конца сражались за идеи, в то время, как главные идеологи, бросив своих подчиненных, занялись спасением себя и своего имущества.

Медленно, но неуклонно двигалась эта кучка людей и животных против гремевшего бесконечного потока отступавших. Прохожие останавливались и молча смотрели им вслед. Смотрели с испугом, с сожалением, как смотрят на людей, уже обреченных. Все было ясно и понятно до жути [Корсак 1931]. 
Вместе с тем, именно эти последние защитники Одессы внушают повествователю, неспособному на подобный героизм, надежду.

Соберет ли кто-нибудь и когда-нибудь их имена, сохранит ли добровольный их подвиг чье-либо сердце?.. Есть и высокое в мире, и даже торжествующему злу не поглотить его [Корсак, 1931].

Эту веру в добро „маленький человек” забирает с собой, покидая Россию. На госпитальное судно герой Корсака попадает в каком-то смысле полусознательно, прикинувшись раненым. Удивительно, что голодный, грязный, одинокий в обезумевшей толпе, он еще вообще способен замечать вокруг добро. В этом контексте слишком суровой кажется оценка эвакуирующихся из Одессы, данная Константином Паустовским в автобиографической Повести о жизни (часть Начало неведомого века, 1956). Повествователь, вслушиваясь в гудки отходящих пароходов, констатирует:

Они прозвучали как отходная людям, покидавшим отечество, отказавшимся от своего народа, от русских полей и лесов, весен и зим, от народных страданий и радостей, отрекшимся от прошлого и настоящего, от светлого гения Пушкина и Толстого, от великой сыновней любви к каждой травинке, к каждой капле воды из колодца простой и прекрасной нашей земли" [Паустовский 1956].

В контексте столь строгого упрека возникает вопрос, можно ли простого человека, лишенного всего, брошенного и униженного всеми властями, годами скитающегося по разоренной стране, осуждать за то, что он, доведенный до предела своих физических и психических возможностей, не хочет больше страдать и не думает при этом о гении Пушкина и прелестях родной земли? Произведения Корсака, как нам кажется, дают однозначный ответ на данный вопрос и становятся голосом в защиту миллионов „маленьких людей” , их права выбора своего собственного пути, права жить простой и обыкновенной жизнью без обвинений не только в недостаточном патриотизме, но даже в измене родине.

\section{Библиография}

Алданов М. 1928. В. Корсак. „Плен”, „Современные записки”, № XXXIV.

Горкин А. (ред.) 2006. Литература и язык. Современная илюстрированная энциклопедия, электронный ресурс: http://www.e-reading.club/bookreader.php/68589/

Enciklopediya_Literatura_i_yazyk_(s_illyustraciyami).html (доступ 10.09.2017).

Зверев Г. 1990. Веньямин Корсак. „У белых", „Юность”, № 10.

Корсак В. 1927. Плен, Париж: Родник.

Корсак В. 1930. У красных, Париж: Родник. 
Корсак В., 1931. Великий исход, электронный ресурс: http://xxl3.ru/belie/korsak.htm (доступ 10.09.2017).

Корсак В. 1931. У белых, Париж: Родник.

Морозова Т. 2012. Из глубины, „Знамя”, № 1, электронный pecypc: http:/ / magazines. russ.ru/znamia/2012/1/mo19.html (доступ 10.09.2017).

Носик Б. 2005. Русский ХХ Век на кладбище под Парижем, Санкт-Петербург: Золотой век.

Осоргин М. 1933. В. Корсак. „Под новыми звездами”, „Современные записки”, т. LII.

Паустовский К. 1956. Повесть о жизни. Начало неведомого века, электронный ресурс: http:/ / www.lib.ru/PROZA/PAUSTOWSKIJ/lifebook3.txt_with-big-pictures.html (доступ 10.09.2017). 